\title{
The blue planet earth systems approach (BEPESA) for the study of water related systems
}

\author{
O. Ben-Zvi-Assaraf ${ }^{1}$, N. Orion ${ }^{2} \&$ D. Ronen ${ }^{3}$ \\ ${ }^{I}$ The Science Teaching Department, Ben-Gurion University of the Negev, \\ Israel \\ ${ }^{2}$ The Science Teaching Department, Weizmann Institute of Science, Israel \\ ${ }^{3}$ Zuckerberg Institute for Water Research, \\ Department of Environmental Hydrology \& Microbiology, Israel
}

\begin{abstract}
This paper calls for an environmentally-oriented program that is based not only on environmental education towards awareness, but a program that helps develop environmental insight and understanding. The Israeli chapter of the IHP and the Israel National Commission for UNESCO present the Blue Planet Earth Systems Approach (BEPESA). The main goal of BEPESA, presented here, is to encourage junior-high school students to develop system-thinking as a basis for environmental literacy. BEPESA is an earth system-based curriculum package focusing on water-related issues in an environmental context. It has been applied and tested in Israel since 2000 in association with cognitive-based research that disclosed unusual positive results. High order thinking skills, such as system thinking skills, can indeed be taught at the junior high-school level, leading to considerable gains in students' reasoning and abilities. Furthermore, students involved in the learning process through knowledge integration activities, scientific inquiry, and with a concrete connection with the outdoor learning environment, achieved meaningful improvement in their systems-thinking skills. Keywords: system thinking, earth science education, sustainable development.
\end{abstract}

\section{Introduction}

In the $21^{\text {st }}$ century, our contact with and understanding of natural aquatic environments has become an issue of paramount importance for sustaining and 
improving the quality of human life on Earth. Such an endeavor suggests education to be a key factor in our society, a process that should start as early in life as possible.

\subsection{Understanding how dynamic systems work}

The water cycle is a complex system in order that students will meaningfully understand it they should understand environmental phenomena in the context of interrelationship among earth system. We postulate that in order to understand such a complex system (the water cycle) meaningfully, students must conceive the following relationships between earth's systems: (a) the hydrosphere and the geosphere (e.g. chemical weathering by dissolution and precipitation of minerals from seawater); (b) the hydrosphere and the atmosphere (e.g. evaporation and condensation); and (c) the biosphere and the atmosphere (e.g. transpiration).

Many definitions and descriptions of dynamic systems abound in the literature. It seems that the following characteristics of dynamic systems critical to understanding how systems operate:

1. Systems include multiple interacting parts, which consist of stocks (reservoirs) and flows (movement between reservoirs);

2. Understanding the whole system consists of more than the just understanding each of the parts - it requires a holistic view of the system as an entity itself and how it operates;

3. Material that moves through a system can change form, sometimes into forms that are not visible, but the material does not leave or "disappear" from the system;

4. Movement through the system can take place via multiple different processes;

5. Movement though the system is not necessarily linear/cyclical, but rather dynamic;

6. Systems have both temporal and spatial characteristics;

7. Interactions between parts of a system operate continuously and dynamically; 8. Disturbances to one part of the system may cause changes throughout the whole system [1-3].

Kali et al. [4], suggested that the ability of students to deal with such systems is based on their ability to develop a dynamic-cyclic-systemic perception of our planet. Teaching earth systems, then, requires the development of system thinking amongst students.

System thinking includes recognizing patterns and interrelationships, and learning how to structure those interrelationships into more efficient ways of thinking [5]. Senge [8] refers to systemic thinking as a conceptual framework of knowledge, principles and tools that enable observing the interrelationship and the mutual connections in order to determine changeable patterns and repeated phenomena. Orion [7] has argued that the study of natural cycles (i.e. rock cycle; the water cycle, the food chain, the carbon cycle) should be discussed within the context of their influence on people's daily life, rather than being isolated into 
scientific domains (physics, chemistry and biology). He also suggested that such an understanding, which can be described as "understanding the Earth as a system", may serve as a basis for developing an environmental curriculum.

\subsection{The Blue Planet Earth Systems Approach (BEPESA)}

In order to fulfil the above goal, UNESCO presents to all Spanish speaking countries of the world the book entitled "The Blue Planet - The Water Cycle in the Earth's Eco-Systems", which contains a program for the study of waterrelated issues for the junior-high school level. The main goal of the program is to encourage students to develop the above level of system thinking as a basis for environmental literacy. In each chapter, the topics are presented within the context of the relationships between the hydrosphere and other earth systems. BEPESA emphasizes that understanding is not about single propositions or concepts, but rather about interrelated sets of ideas that provide a framework for understanding environmental phenomena. The following scientific principles were included in the program: a) The existence of dynamic relationships between different Earth "compartments" (e.g, biosphere, hydrosphere); b) Energy and substance transport between biogeochemical cycles that affect the systems of Earth, and c) The need for environment-friendly development, along with the implementation of technological solutions to reduce negative environmental impacts and to preserve nature's capacity as a life-supporting system.

\subsection{What are the students' needs for a supportive learning environment?}

Although the water cycle is strongly related to our daily life, especially in a semi-arid area, to make it relevant in students' eyes the mere fact that it is a realworld subject is not enough. In order to address the students' need for a supportive learning environment, the all-learning process should be considered in light of its relevancy to the students' daily environment. Therefore, we incorporate in the program several different teaching approaches and learning strategies, such as a focus on the water cycle as an example of the relationships seen amongst the various earth systems. In order to enable students to construct the dynamics of material transformation within the water system, the learning process includes knowledge integration activities (e.g. creation of concept maps, drawings, etc.). Furthermore, in order to understand the components of the environment, one should be in contact with nature. During the learning process, the students were engaged in indoor and outdoor learning activities. In the authentic outdoor environment they explored a spring, a stalagmite cave, and a water treatment plant. While exploring these components of the water cycle, the students created mental models of the interrelationships between the natural earth systems and man. The direct exposure to outdoor natural scenarios and processes may enable students to create a concrete local water cycle, subsequently be enlarged into a more abstract global system. Moreover, Environmental awareness is the consequence of an interaction between the student and the environment outside the classroom. 


\section{Purpose}

The current study deals with the development of system thinking skills of junior high school students in the context of science education. More specifically, it addresses the study of the water cycle as part of a wider set of recycling systems, which include the geosphere, biosphere, and atmosphere. The objectives of this study were to identify the higher-order thinking skills that are involved in the system thinking process, and to evaluate the influence of learning the program on the development of system thinking among junior high school students.

\section{Methods}

The sample population included about $3008^{\text {th }}$ grade students from four different schools of an urban Israeli junior high school who studied an earth systemsbased curriculum that focused on the hydro cycle. The research combined qualitative and quantitative methods and involved a variety of research tools that were implemented in order to evaluate students' knowledge and understanding before, during, and following the learning process.

Qualitative tools such as interviews, concept maps and Repertory Grids were used to collect the data and were implemented at the beginning, middle and end of the learning process.

The Repertory Grid technique is a knowledge-elicitation technique devised by the clinical psychologists Kelly in 1955 and used since than as a tool to assess user's conceptual model and thus, to identify system aspects which are most commonly misunderstood. After identifying a small set of elements (objects, entities), the user was asked to define some constructs that characterize those elements. The technique is used for eliciting and analyzing the students' knowledge and personal constructs [6]. It combines two processes of creating personal mental constructs. First, the constructs are elicited by comparing groups of three elements. For example, Ocean, Rivers, and Aquifer, may create the construct, "High salinity", which characterizes the element Ocean compared to the other two elements. Second, students are requested to use the constructs in order to rate every element in the grid on a scale of 1 to 5. Table 1 in the results section is an example of a Repertory Grid created by a student at the end of the learning process using the construct "salinity" ( 1 is low and 5 is high) in order to explore the relationship between the system components.

Concept maps - are used for examining the way learners restructure their knowledge and to elicit the student's perception of the relationships that exist among the concepts [10]. In order to identify the individual conceptual changes, we analyzed the significance of the link between concepts and their organization within the map. Moreover, we examined the extent to which the map shows dynamic relationships between the system components, and rich patterns of cross-relations.

\section{Results}

The analysis of the students' Repertory Grid personal constructs revealed that in the beginning of the learning process students used more general constructs that 
describe the system components and its characters. For example, the amount of water that exists in each of the water cycle components, and the salinity of the water. During the learning process, some students were able to use scientific knowledge to differentiate between the elements of the water cycle. Therefore, the elicited constructs represent a more systemic perception of the water cycle, which presents the dynamic nature of the system. For example, the amounts of water that moves through each one of the water cycle components and the rate of its movement. Some students presented also relationships between humans and the water cycle (Table 1).

The improvement of the students' acquaintance with the water cycle components and processes was manifested and clearly revealed in the concept maps. Students' improvement of this ability to identify relationships among components can be seen in their concept maps. The data analysis of the sentences within the concepts maps revealed that many of the sentences that appeared in the pre-test concept maps emphasize the distribution of water on earth: fresh and salty water focus on the atmospheric cycle.

Table 1: Repertory Grid created by a student, before and at the end of the learning process.

\begin{tabular}{|c|c|c|c|c|c|c|c|}
\hline \multicolumn{8}{|c|}{ Repertory Grid created by a student before the learning process. } \\
\hline \multirow{3}{*}{$\begin{array}{c}\text { Low } \\
\text { salinity } \\
1\end{array}$} & River & Sewage & Ocean & Atmosphere & Lake & Aquifer & \multirow{3}{*}{$\begin{array}{c}\text { High } \\
\text { salinity } \\
5\end{array}$} \\
\hline & \multirow[t]{2}{*}{3} & \multirow[t]{2}{*}{2} & \multirow[t]{2}{*}{5} & \multirow[t]{2}{*}{1} & \multirow[t]{2}{*}{3} & \multirow[t]{2}{*}{3} & \\
\hline & & & & & & & \\
\hline \multicolumn{8}{|c|}{ Repertory Grid created by a student at the end of the learning process. } \\
\hline \multirow{3}{*}{$\begin{array}{c}\text { Low } \\
\text { salinity } \\
1\end{array}$} & \multirow{3}{*}{$\begin{array}{c}\text { River } \\
3\end{array}$} & \multirow{3}{*}{$\begin{array}{c}\text { Sewage } \\
4\end{array}$} & \multirow{3}{*}{$\begin{array}{c}\text { Ocean } \\
5\end{array}$} & \multirow{3}{*}{$\begin{array}{c}\text { Atmosphere } \\
1\end{array}$} & \multirow{3}{*}{$\begin{array}{c}\text { Lake } \\
3\end{array}$} & \multirow{3}{*}{$\begin{array}{c}\text { Aquifer } \\
3\end{array}$} & \multirow{3}{*}{$\begin{array}{c}\text { High salinity } \\
5\end{array}$} \\
\hline & & & & & & & \\
\hline & & & & & & & \\
\hline Man does & River & Sewage & Ocean & Atmosphere & Lake & Aquifer & Man changes \\
\hline not change & 3 & 5 & 2 & 1 & 3 & 4 & the water's \\
\hline quality & & & & & & & 5 \\
\hline 1 & & & & & & & \\
\hline
\end{tabular}

A pre and post analysis of the concept maps showed a significant improvement in the number of interrelations that students understood about earth systems in general and the water cycle in particular. Tami's maps reveal that she has improved mainly her ability to identify the relationship between humans and the water cycle. While completing the concept maps, the students confronted their difficulties in identifying the system components; they created relationships among the components and organized and placed them within a framework of relationships. The post-test maps are substantially richer and include more concepts that reflect the variety of components within the earth system. Analysis of sentences of the concept maps revealed that students significantly increased 
the number of sentences in which water fluxes were described. Students that developed system thinking improved their ability to identify relationships amongst components. For example, Figure 1 represents Tami's post concept

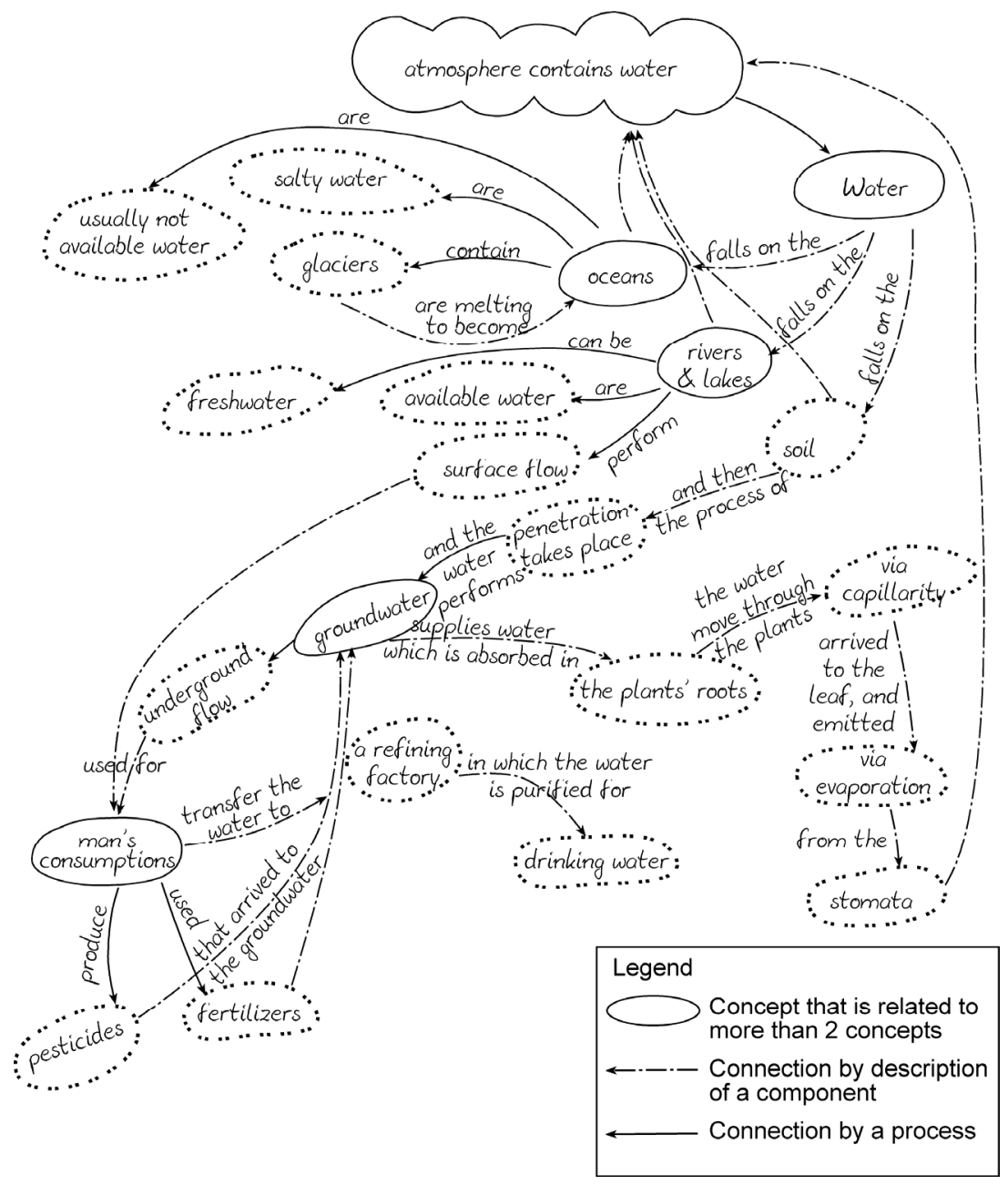

Figure 1: $\quad$ Post-test concept map of a 14 years old girl ("Tami's post-test concept map").

maps, which demonstrates her ability to identify relationships between humans and the water cycle. At the end of the learning process, she suggested that (a) man influences groundwater through pollution by fertilizers and pesticides;

(b) man can be influenced by groundwater as a consumer, and (c), man can change the water's quality through purification. In general, this study revealed that junior high-school students could focus on recognizing the inter-connections between the parts of a system and then to synthesize them into a unified view of 
the whole. It was also found that students' ability to use system thinking as a cognitive tool in facing complexity is a lengthy process that requires a significant cognitive effort. However, students who were involved in the learning process through knowledge integration activities, scientific inquiry, and outdoor learning, achieved a meaningful improvement in their systems-thinking skills. These results indicate that systems thinking abilities, that are considered to be high order thinking skills, may be achieved in junior high school students with a supportive learning environment.

\section{Conclusion}

The Blue Planet program [9] is a product of complex long-term planning that involved searching for environmental problems related to students' lives and interests, developing interdisciplinary environmental stories, creating an authentic learning environment, and supporting teachers in the learning process.

The introduction of an interdisciplinary environmental program within the science curriculum involved environmental and earth scientists, educators, teachers, and students. It should be mentioned that this spiral model of research and the development and implementation of an environmentally oriented curriculum, was adopted by the Israeli Chapter of the International Hydrological Program (IHP) of UNESCO. It was UNESCO understanding that this syllabus will help improve people's understanding and awareness of the importance of water to our planet as a necessary and long-lasting commodity for mankind.

\section{References}

[1] Ben-Zvi Assaraf, O. \& Orion, N., Development of system thinking skills in the context of Earth System education. Journal of Research in Science Teaching, 42, pp. 518-560, 2005.

[2] Fortus, D., Hug, B. Krajcik, J., Kuhn, L., McNeill, K., Reiser, B., Rivet, A. \& Rogat, A., Sequencing and Supporting Complex Scientific Inquiry Practices. Paper presented at the annual meeting of the National Association for Research in Science Teaching, San Francisco. April, 2006.

[3] Hmelo-Silver, C. \& Azevedo, R., Understanding complex systems: Some core challenges. Journal of the Learning Sciences, 15, pp. 53-61, 2006.

[4] Kali, Y., Orion, N. \& Eylon, B., Effect of knowledge Integration Activities on Students' Perception of the Earth's Crust as a Cyclic System. Journal of Research in Science Teaching, 49(6), pp. 545-565, 2003.

[5] Kim, D. H., Introduction to system thinking. In: System Thinking Tools and Applications, ed. D. H. Kim, Pegasus communications Inc: USA, 1999.

[6] Latta, G. F. \& Swigger, K., Validation of the repertory grid for use in modelling knowledge. Journal of the American Society for Information Science, 43(2), pp.115-129, 1992.

[7] Orion N., An Earth Systems curriculum development model. In: V. J. Mayer (ed.) Global Science Literacy, Kluwer Academic Publisher: Dordrecht, the Netherlands, pp. 159-168, 2002. 
168 Environmental Problems in Coastal Regions VII

[8] Senge, P. M., The Fifth Discipline: The Art and Practice of the Learning Organization, Doubleday: New York, 1990.

[9] The Blue-Planet - the water cycle within the earth systems, workbook, http://stwww.weizmann.ac.il/g-earth/geogroup/

[10] White, R. \& Gunstone, R. Probing Understanding. Palmer Press: London, 1992. 